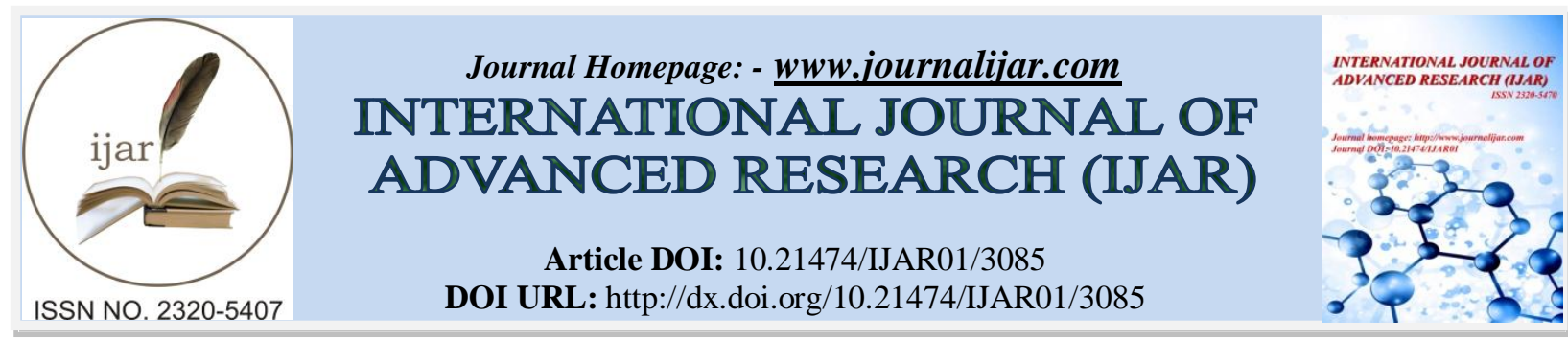

RESEARCH ARTICLE

\title{
ASSESSMENT OF GLAUCOMA AWARENESS AND KNOWLEDGE AMONG DIABETIC PATINENTS IN HAIL, SAUDI ARABIA
}

Alsuwaydaa and Meshari Sulaiman.

University of Hail, Ophthalmology Department.

\section{Manuscript Info}

Manuscript History

Received: 03 November 2016

Final Accepted: 28 December 2016

Published: January 2017

\begin{abstract}
Green banking is a new concept of banking were in all other activities of banking remains the same, but extra protection is given on sustainability environmental protection through paper less banking. It is that part of banking which aim at reduction of operational cost, improving efficiency and total productivity. This paper makes an attempt to find out the awareness and adoptability of concept of green banking. We know thatIndia is a developing nation were nearly $40 \%$ of population are youths. It makes an investigation into the various modes of e - banking services available to the customers and extent they use the services.
\end{abstract}

Copy Right, IJAR, 2016,. All rights reserved.

\section{Introduction:-}

Glaucoma is the second leading cause of blindness in the worldandthe estimated prevalence of Glaucoma around the world is estimated 60 million people with glaucomatous optic neuropathy and an estimated 8.4 million people who are blindas the result of glaucoma. The prevalence in Saudi Arabia has not been determined however, These numbers are set to increase to 80 million and 11.2 million by 2020 .

People with diabetes are vulnerable to develop glaucoma as are non-diabetics .Alake of knowledge about the disease may cause patients to present late and miss the opportunity to reap the benefits of early intervention.

\section{Objectives:-}

To evaluate the awareness and knowledge on Glaucoma among diabetic patients in Hail city and yearly screening measure.

\section{Materials \& Methods:-}

a community based cross sectional study was conducted in Hail city Among diabetic patients .the questionnaire was designed to be three parts:

first part related to personal information (age, gender, education level) and diabetic duration. Second part focused on the awareness and knowledge through 8 questions (four questions evaluating their awareness and four assessing their knowledge). The third part had two questions dealing with the source of information about glaucoma and any screening done regularly. Diagnosed cases of glaucoma were excluded from participating. The questionnaire began with the entry level question "have you heard about glaucoma"

However, not having heard the term itself meant lack of awareness 


\section{Results:-}

A total of 134 diabetic patients were collected,Age range 18 - 70 The mean age was 53years.Males were about 76 participants (56.7\%) and female $58(43.3 \%)$, Among the $32(23 \%)$ illiterate participants 22 were male and 10 were female $102(77 \%)$ participants were educated at different level, 82(61.2\%) have more than 10 years duration with diabetes, A total of $55(41 \%)$ participants had heard about glaucoma, And the remaining who have not heard are consider as not aware, $(26.2 \%)$ were aware, and $(21.2 \%)$ had some knowledge about glaucoma. Awareness of glaucoma in terms of age and gender no difference.

Literate participants were more likely to be aware and likely to be knowledgeable than illiterate participants .The level of education had a significant association with both awareness and knowledge.

Source of information about glaucoma among the respondents was also assessed during the survey. Source of information for 28 (50.9) participants was from family or friends. Another 15 (27\%) participants had received information from visiting hospitals, medical personnel, eye camps or other healthcare recourses. TV and other media was source of information for only $12(21 \%)$ of the participants.
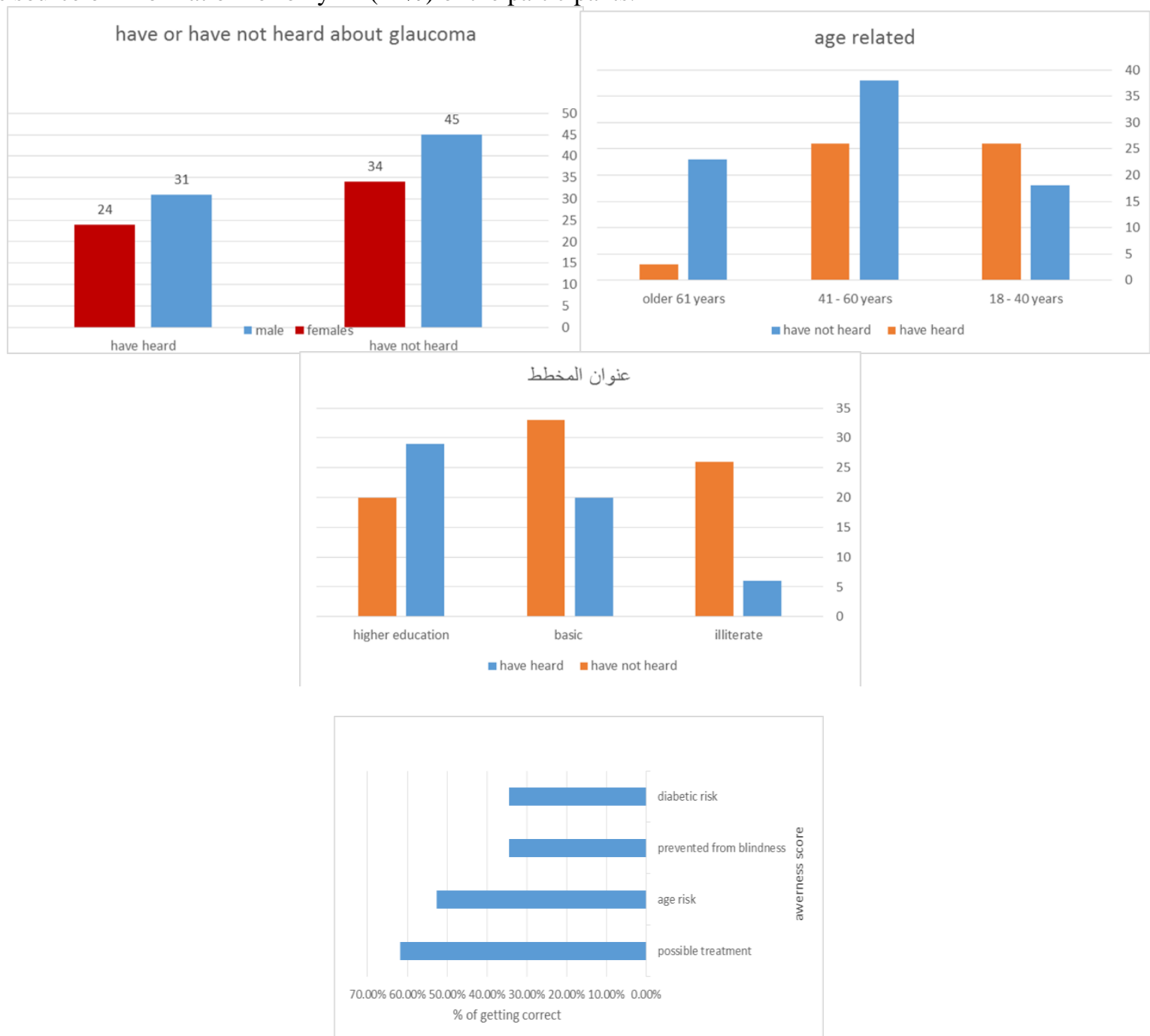


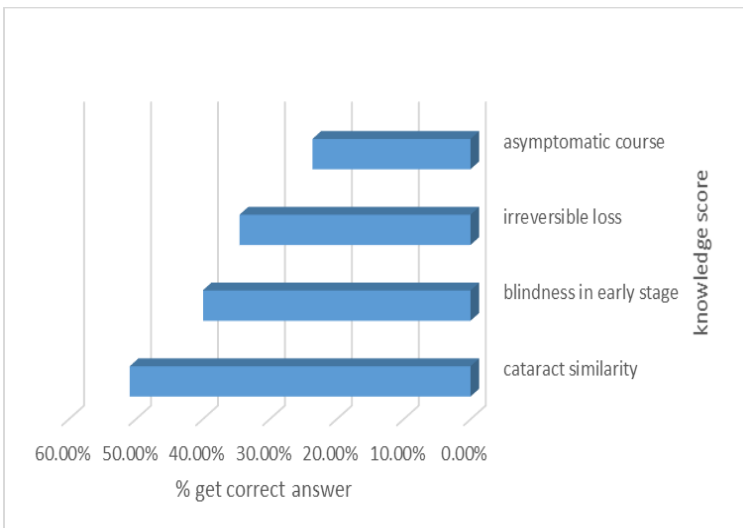

\section{Discussion:-}

This study assesses the awareness and knowledge about glaucoma among diabetic patientsThe goal of this study to evaluate the understanding of glaucoma, that is, a silent clinical course, irreversible loss, and the importance of screening .some of participants had heard the term glaucoma (جلوكما) even though, they were a few actually aware,

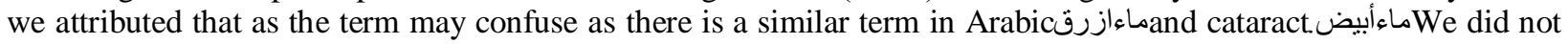
find any relationship between age or gender and glaucoma awareness, like many other studies In this study, awareness and knowledge was better among individuals with higher education.As expectedSmall percentage knew that glaucoma has asymptomatic course and this must raise alertLack of awareness could often lead to underdiagnosis and late presentation, as noted in several previous studies and therefore, adversely affected the eye careseeking behaviorSatisfied percentage knew could be vision loss irreversiblefriends and family as the most common source of glaucoma information. Studies from the UK have reported the successful role of media in increasing the awareness about glaucoma. *

\section{Conclusions:-}

glaucoma awareness and knowledge is suboptimal in Hail among diabetic patients and their knowledge about yearly screening benefits is nearly poor. We recommend the use of public awareness campaigns through various media.

\section{Reference:-}

1. kinsky ophthalmology - glaucoma chapter "introduction"

2. Prevalence of blindness WHO. http://www.who.int/blindness/Vision2020_report

3. Indian J Ophthalmology .

4. Awareness, knowledge, and practice: A survey of glaucoma in north Indian rural residents,ParveenRewri

5. Baker H, Murdoch IE. Can a public health intervention improve awareness and health-seeking behavior for glaucoma? Br J Ophthalmol. 2008;92:1671-5. 